\title{
Central neurological complications and potential neuropathogenesis of COVID-19
}

\author{
Jianing Wang ${ }^{1} \mathbb{D} \cdot$ Ping Wang $^{1} \cdot$ Chunyi $^{\mathrm{Li}^{1}} \cdot$ Yihuan Huang ${ }^{1} \cdot$ Chunxiao Yang $^{2} \cdot$ Lei Zhang $^{1}$
}

Received: 23 May 2020 / Accepted: 11 August 2020 / Published online: 29 August 2020

(c) Società Italiana di Medicina Interna (SIMI) 2020

\section{Dear Editor,}

In December 2019, a new corona virus pneumonia (COVID19) first broke out and soon reached worldwide. The causative pathogen is SARS-CoV-2, which is recognized as the 7 th member of human corona virus $(\mathrm{HCoV})$ family. Approximately, 8 months of COVID-19 rapid spreading has led to over 10 million diagnosed cases and hundreds of thousand fatalities in multiple countries. The World Health Organization (WHO) has characterized the COVID-19 outbreak as a "Public Health Emergency of International Concern", and it's the first pandemic caused by a corona virus, which poses an imminent threat to the global health care system.

SARS-CoV-2 is a beta-coronavirus. The spike glycoprotein of SARS-CoV-2 can attach to host cell membrane by recognizing and binding to the angiotensin-converting enzyme 2 (ACE2) receptor, and transmembrane protease type 2 (TMPRSS2) also plays a critical role in the viral invasion [1]. Based on the homology modeling of receptor binding domain subdomain-1, the structure of SARSCoV-2 shows about $73.96 \%$ sequence identity with SARS$\mathrm{CoV}$, which might explain the resemblance in biochemical mechanism [2].

SARS-CoV-2 has been reported to exert toxic effects on multiple tissues and organs, such as lung, heart, esophagus,

Jianing Wang and Ping Wang contributed equally to this article and should be considered co-first authors.

The article belong to COVID 19.

Chunxiao Yang

yangchunxiao72@163.com

$\triangle$ Lei Zhang

13726209240@139.com

1 Department of Cerebrovascular Disease, The Fifth Affiliated Hospital, Sun Yat-Sen University, Zhuhai 519000, China

2 Department of Neurology, The Second Affiliated Hospital, Harbin Medical University, Harbin 150086, China kidney, bladder, ileum, as well as the central nervous system (CNS). According to a study in Wuhan, dizziness (16.8\%) and headache (13.1\%) are the most common CNS symptoms, followed by impaired consciousness $(7.5 \%)$, acute cerebrovascular disease (2.8\%), ataxia ( $0.5 \%)$, and seizures $(0.5 \%)$ [3]. In another study outside of Wuhan, the incidence of headache even reaches up to $34 \%$ [4]. Although there's no direct evidence supporting a specific relationship between SARS-CoV-2 and human neuropathology, a spectrum of central neurological manifestations of COVID-19 have already been described in case reports and retrospective studies, including encephalitis, meningitis, encephalopathy, acute disseminated encephalomyelitis (ADEM), and acute cerebrovascular disease. The corresponding neuropathologic changes are also observed in the COVID-19 patients at autopsy [5-9] (Table 1).

Based on the experience of other HCoVs, there are three potential factors related to neurological manifestations: direct invasion by virus, host immune response after infection, as well as the associated pulmonary and systemic diseases. The damage of direct invasion depends (in part) on the ability of virus to penetrate the CNS (neuroinvasion), infect neurons and glial cells (neurotropism), and induce neurological diseases (neurovirulence) [10]. It still remains unclear to what extent the CNS symptoms can be attributed to direct SARS-CoV-2 invasion or if these symptoms are mainly related to the secondary mechanisms.

Several HCoVs, such as HCoV-229E, HCoV-OC43, and SARS-CoV, are considered to be neuroinvasive since the infectious particles or viral RNAs are detected in the CNS. They act typically by two anatomical routes: hematogenous dissemination and neuronal retrograde dissemination [10]. Once the HCoVs reaching cerebral circulation by hematogenous dissemination during viremia, the viruses may penetrate the blood-brain barrier (BBB) through receptors expressed on the brain micro-vascular endothelial cells and subsequently impair the endothelial cell-cell junctions, resulting in BBB dysfunction and hyperpermeability. 
Table 1 Neurological manifestations and associated neuropathological findings in COVID-19 patients

\begin{tabular}{|c|c|c|c|c|}
\hline Manifestations & Presentations & Neuropathological findings & Type of study & References \\
\hline Encephalitis/meningitis & $\begin{array}{l}\text { Three out of six patients presented } \\
\text { with somnolent }\end{array}$ & $\begin{array}{l}\text { Cerebral cortex encephalitis with } \\
\text { perivascular and parenchymal } \\
\text { inflammatory infiltrates, and } \\
\text { shrunken neurons }\end{array}$ & Correspondence & {$[5]$} \\
\hline Encephalopathy & $\begin{array}{l}\text { Four out of } 18 \text { patients presented } \\
\text { with myalgia, headache, and } \\
\text { decreased taste, progressed to } \\
\text { consciousness and multiorgan } \\
\text { failure }\end{array}$ & $\begin{array}{l}\text { Hypoxic changes with no specific } \\
\text { pathology }\end{array}$ & Retrospective study & [6] \\
\hline $\begin{array}{l}\text { Acute disseminated encephalomy- } \\
\text { elitis }\end{array}$ & $\begin{array}{l}\text { Fatigue and exertional dyspnea, } \\
\text { progressed to shock state, respira- } \\
\text { tory failure }\end{array}$ & $\begin{array}{l}\text { Features resembling both vascular } \\
\text { and demyelinating aetiologies } \\
\text { among with range of sub-cortical } \\
\text { white matter pathology }\end{array}$ & Case report & [7] \\
\hline \multirow[t]{2}{*}{ Acute cerebrovascular disease } & $\begin{array}{l}17 \text { patients presented with cerebral } \\
\text { ischaemia, five with intracer- } \\
\text { ebral haemorrhage and one with } \\
\text { leukoencephalopathy of posterior } \\
\text { reversible encephalopathy }\end{array}$ & $\begin{array}{l}\text { Thrombotic microangiopathy and } \\
\text { endothelial injury }\end{array}$ & Retrospective study & {$[8]$} \\
\hline & $\begin{array}{l}\text { Two patient presented with coma } \\
\text { and multiorgan failure }\end{array}$ & Microthrombi and acute infarcts & Correspondence & [9] \\
\hline
\end{tabular}

HCoVs may pass the BBB by hijacking host immunocytes as well, which is termed "the Trojan horse mechanism". Recently, the presence of SARS-CoV-2 viral-like particles has been observed in capillary endothelia of a frontal lobe specimen [11], and the entry of SARS-CoV-2 into the CNS via endothelial cells has also been documented [5]. These results indicate that the hematogenous dissemination can be a potential route of entry.

It remains unclear whether SARS-CoV-2 is able to penetrate the CNS via neuronal retrograde route. Olfactory dysfunction is one of the most common symptoms in COVID-19, which is often related to viral infection of the olfactory epithelium. But according to the Human Protein Atlas (HPA) database, it is non-neuronal cells (for example, olfactory epithelial support cells, stem cells, and vascular pericytes) that express ACE2 and are vulnerable to SARS-CoV-2 infection, rather than olfactory sensory or bulb neurons [12]. Primary infection of non-neuronal cells possibly causes olfactory dysfunction by leading to significant inflammatory responses, altering the function of olfactory neurons, and influencing the olfactory signals. Besides, no specific changes referable to the virus have been observed in the olfactory bulbs or tracts at autopsy [6]. Thus, further studies may be needed to determine whether there are other neuronal pathways, such as nerves from the lung or gastrointestinal tract.

Cases have emerged in which patients had clinical manifestations of encephalitis and positive results of SARSCoV-2 in cerebrospinal fluid (CSF). However, these findings cannot prove the neurotropism of SARS-CoV-2 directly, since the CSF may also contain the virus from the meninges and cerebral microvasculatures. In fact, based on the HPA and Genotype Tissue Expression (GTEx) databases, the CNS cells express rather low levels of TMPRSS2, which are required by SARS-CoV-2 for host cell entry [12]. Lately, Bullen et al. reported the potential neurotropism of SARSCoV-2 by employing a human induced pluripotent stem cell (iPSC)-derived BrainSphere mode [13]. Virus infection and replication can be observed in BrainSphere despite the TMPRSS2 gene expression being below the detection limit, suggesting alternative processing. In fact, a few proteins are found to act as co-factors for viral entry. A Disintegrin and Metalloproteases 17 (ADAM17) is a co-factor that can compete with TMPRSS2 or work independently for ACE2 shedding, and down regulation of ADAM17 by siRNA may result in a decreased in SARS-CoV infection [14]. According to HPA database, ADAM17 is more widely distributed than TMPRSS2 in human brain tissue [12]. Nevertheless, it should be emphasized that the current information is far from complete. Several aspects still remain to be elucidated before drawing a final conclusion about the neurotropism of SARS-CoV-2, such as the potential host receptors and infection co-factors, the susceptibility of CNS resident cells, as well as possible host-pathogen interactions on ACE2/ TMPRSS2 expression.

Viral infection is often associated with cell death, and numerous molecular pathways have been proposed to explain the neurovirulence of HCoVs [10]. For example, parthanatos, caspase independent-apoptosis and programmed necrosis pathways may be involved in the neuropathogenesis of HCoV-OC43. These molecular pathways can also interact with one other by sharing the same cellular factors (such as 


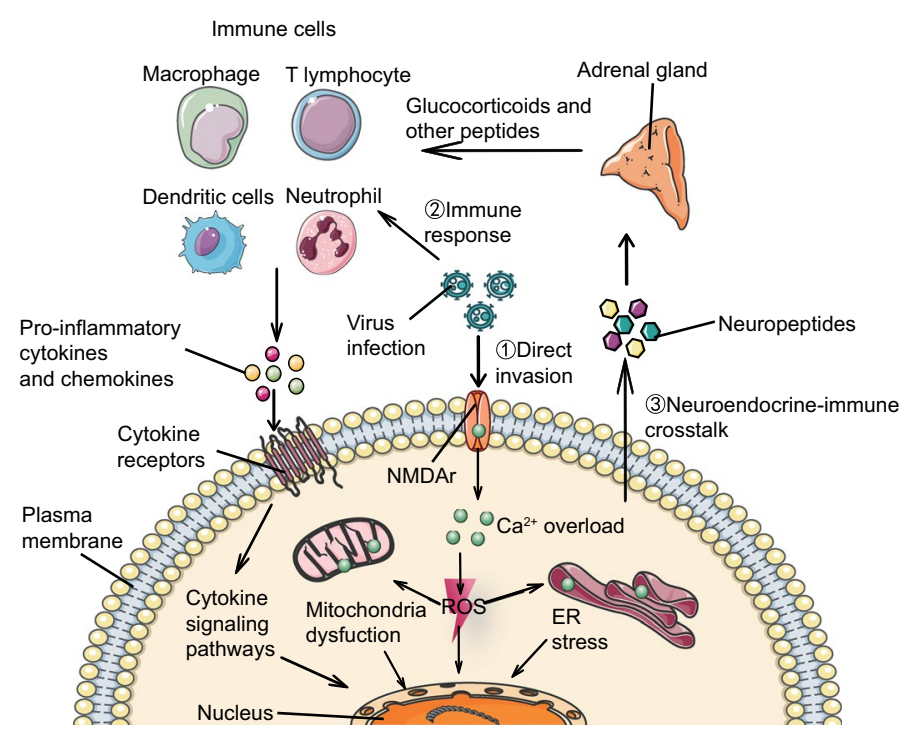

Fig. $1 \mathrm{HCoVs}$ probably exhibit neuropathological consequences through multiple routes. (1) Direct invasion. After invasion, the production and release of virus may induce cell death by several pathways. (2) Immune response. The virus can lead to over-activation of host immune response, releasing a large number of pro-inflammatory cytokines and chemokines (e.g., IL-6, IL-1 $\beta$, IL-2, IL-8, IL-17, G-CSF, GM-CSF, IP10, MCP1, CCL3, and TNF). Cytokine signal

calcium overload, mitochondrial dysfunction or endoplasmic reticulum stress, excitatory amino acid toxicity), and active compounds (such as reactive oxygen species) (Fig. 1). However, it remains to be determined whether and how SARSCoV-2 affects the function of CNS cells.

Meanwhile, SARS-CoV-2 can contribute to CNS symptoms indirectly. It is known that cytokine storm syndrome and immunosuppression are important factors accelerating the progression of COVID-19 [15]. Some HCoVs can contribute to CNS demyelinating diseases by triggering immune dysfunction, and similar cases have been reported in SARS-CoV-2 as well [7]. A 71-year-old man, who had been hospitalized for cardiac disease initially, was diagnosed with COVID-19 and died after more than 2 weeks. In the subsequent post-mortem analysis, pathologic changes have been observed in the brain tissue with features resembling both acute hemorrhagic leukoencephalitis and ADEM. This indicates that SARS-CoV-2 may induce CNS tissue damage though cytokine pathways and the patients who burdened by severe infection might be more prone to serious neuropathological consequences. In turn, viral infection of CNS may also lead to the impairment of immune response, partly because the virus can influence the neuroendocrine system in releasing glucocorticoids and other peptides, which is called "neuroendocrine-immune crosstalk" (Fig. 1). Besides, an autopsy of 18 COVID-19 patients showed that only hypoxic changes, rather than specific changes referable to viral infection, pathways will subsequently induce the cell death and tissue damage. (3) Neuroendocrine-immune crosstalk. Aberrant release of neuropeptides from the infected neurons may act at the endocrine glands, such as adrenal gland. These neuropeptides might cause anomalous release of glucocorticoids and other peptides, which may contribute to the dysregulation of immune system

have been observed in the brain specimens, even in some patients presenting with CNS symptoms [6]. This is partly because SARS-CoV-2 infection is often associated with pulmonary and systemic diseases that may lead to neurological manifestations.

In conclusion, the SARS-CoV-2 may trigger or exacerbate neuropathologies through direct or indirect ways. Whereas the high mortality and morbidity rates of neurological manifestations, further explorations are needed to develop valid diagnostic and therapeutic approaches, so as to improve the outcome for these patients effectively.

Acknowledgements This study was supported by Grants from the National Natural Science Foundation of China (81971098).

Funding This study was supported by Grants from the National Natural Science Foundation of China (81971098).

\section{Compliance with ethical standards}

Conflict of interest Jianing Wang, Ping Wang, Chunyi Li, Yihuan Huang, Chunxiao Yang and Lei Zhang declare no conflicts of interest.

Statement of human and animal rights This article does not contain any studies with human participants or animals performed by any of the authors.

Informed consent For this type of study, no informed consent is required. 


\section{References}

1. Hoffmann M, Kleine-Weber H, Schroeder S et al (2020) SARSCoV-2 cell entry depends on ACE2 and TMPRSS2 and is blocked by a clinically proven protease inhibitor. Cell 181:271-280.e8. https://doi.org/10.1016/j.cell.2020.02.052

2. Wrapp D, Wang N, Corbett KS et al (2020) Cryo-EM structure of the 2019-nCoV spike in the prefusion conformation. Science 367:1260-1263. https://doi.org/10.1126/science.abb2507

3. Mao L, Jin H, Wang M et al (2020) Neurologic manifestations of hospitalized patients with coronavirus disease 2019 in Wuhan China. JAMA Neurol. https://doi.org/10.1001/jamaneurol .2020 .1127 (Epub ahead of print)

4. Xu XW, Wu XX, Jiang XG et al (2020) Clinical findings in a group of patients infected with the 2019 novel coronavirus (SARS-Cov-2) outside of Wuhan, China: retrospective case series. BMJ 368:m606. https://doi.org/10.1136/bmj.m606

5. von Weyhern CH, Kaufmann I, Neff F, Kremer M (2020) Early evidence of pronounced brain involvement in fatal COVID-19 outcomes. Lancet 395:e109. https://doi.org/10.1016/S0140 $-6736(20) 31282-4$

6. Solomon IH, Normandin E, Bhattacharyya S et al (2020) Neuropathological features of Covid-19. N Engl J Med. https://doi. org/10.1056/NEJMc2019373 (Epub ahead of print)

7. Reichard RR, Kashani KB, Boire NA, Constantopoulos E, Guo Y, Lucchinetti CF (2020) Neuropathology of COVID-19: a spectrum of vascular and acute disseminated encephalomyelitis (ADEM)-like pathology. Acta Neuropathol 140:1-6. https://doi. org/10.1007/s00401-020-02166-2

8. Hernández-Fernández F, Valencia HS, Barbella-Aponte RA et al (2020) Cerebrovascular disease in patients with COVID-19: neuroimaging, histological and clinical description. Brain. https://doi. org/10.1093/brain/awaa239 (Epub ahead of print)
9. Jaunmuktane Z, Mahadeva U, Green A et al (2020) Microvascular injury and hypoxic damage: emerging neuropathological signatures in COVID-19. Acta Neuropathol. https://doi.org/10.1007/ s00401-020-02190-2 (Epub ahead of print)

10. Desforges M, Le Coupanec A, Brison E, Meessen-Pinard M, Talbot PJ (2014) Neuroinvasive and neurotropic human respiratory coronaviruses: potential neurovirulent agents in humans. Adv Exp Med Biol 807:75-96. https://doi. org/10.1007/978-81-322-1777-0_6

11. Paniz-Mondolfi A, Bryce C, Grimes Z et al (2020) Central nervous system involvement by severe acute respiratory syndrome coronavirus-2 (SARS-CoV-2). J Med Virol 92:699-702. https:// doi.org/10.1002/jmv.25915

12. Uhlén M, Fagerberg L, Hallström BM et al (2015) Proteomics. Tissue-based map of the human proteome. Science 347:1260419. https://doi.org/10.1126/science.1260419

13. Bullen CK, Hogberg HT, Bahadirli-Talbott A et al (2020) Infectability of human BrainSphere neurons suggests neurotropism of SARS-CoV-2. Altex. https://doi.org/10.14573/altex.2006111 (Epub ahead of print)

14. Haga S, Yamamoto N, Nakai-Murakami C et al (2008) Modulation of TNF-alpha-converting enzyme by the spike protein of SARS$\mathrm{CoV}$ and ACE2 induces TNF-alpha production and facilitates viral entry. Proc Natl Acad Sci USA 105:7809-7814. https://doi. org/10.1073/pnas.0711241105

15. Mehta P, McAuley DF, Brown M et al (2020) COVID-19: consider cytokine storm syndromes and immunosuppression. Lancet 395:1033-1034. https://doi.org/10.1016/S0140-6736(20)30628-0

Publisher's Note Springer Nature remains neutral with regard to jurisdictional claims in published maps and institutional affiliations. 